\title{
Surveillance \& Society \\ Watch Me Pay: Twitch and the Cultural Economy of Surveillance
}

\section{William Clyde Partin}

University of North Carolina, Chapel Hill, USA

WCPartin@live.unc.edu

\begin{abstract}
This paper describes where and how research into the Amazon-owned livestreaming platform Twitch can profitably engage surveillance studies. It argues that Twitch sits at the intersection of what David Lyon calls "surveillance culture," a culture in which watching and being watched is fundamental to individuals' customs, habits, and ways of interpreting the world; and surveillance capitalism, Shoshana Zuboff's term for an emerging logic of accumulation built on data collection and hoarding. I draw attention to three different actors in the Twitch ecosystem - the viewer, the streamer, and the platform owner-to articulate the different modes of seeing and being seen each position affords. In all cases, I illustrate how visibility is bound up in a complex, multidirectional web of political economic relations. In order to resist technological determinist narratives about platform effects, I consider Twitch as a "boundary object" in order to identify how social, geographical, and cultural context influences actors in each position. I conclude by offering some observations about what Twitch reveals about platform surveillance in general.
\end{abstract}

\section{Introduction}

In July 2018, the St. Louis Dispatch reported that Jason Gargac, a 32-year old Uber and Lyft driver working in the St. Louis area, had been secretly broadcasting a live feed of his passengers to the Amazon-owned livestreaming platform, Twitch (Heffernan 2018a). While this was not strictly illegal-Missouri is a oneparty recording consent state - passengers interveiwed by the Dispatch were understandably outraged when they learned that their rides had been streamed to an audience of several hundred viewers, some of whom made disparaging and sexually-charged comments about riders in real-time. Initially, Uber offered a fivedollar credit to anyone who complained and a promise that they would not be paired with Gargac again. Under increasing public pressure, however, Uber (and, later, Lyft) deactivated Gargac's account and instituted a policy banning drivers from broadcasting while on duty (Heffernan 2018b). Gargac, who reported earning some additional $\$ 3,500$ on Twitch over a period of several months, eventually deleted his channel, which remains inactive as of December 2018.

This episode is unusual not simply because it poses questions about the legality and ethics of livestreaming, nor even due to the novel collision of two forms of platform labor, but because Twitch is most associated with digital games. While Twitch has relaxed its content guidelines to make space for "lifestreamers" like Gargac, "social eating," live gambling, and even on-duty sanitation workers, these channels are a small fraction of the 4.6 million regular broadcasters on the platform, which delivered close to 10 billion hours of live video in 2018. Twitch sits squarely within what David Nieborg and Thomas Poell (2018: 2) call the 
platformization of cultural production, "the penetration of economic, governmental, and infrastructural extensions of digital platforms into the web," which has significant implications for the production, monetization, and distribution of cultural content.

A growing body of literature is beginning to situate Twitch within broader political, cultural, and economic currents. Even so, while scholars in "Twitch studies" (such as it is) rightly acknowledge the surveillant dimensions of the platform, the specific infrastructures and imaginaries of surveillance on Twitch have not been explored in depth, if only because the field is still establishing its empirical and theoretical terrain. Rather than offering a single argument, then, my aim is to suggest what research into Twitch can learn from surveillance studies, a field that offers a perspective that is especially useful for analyzing a platform built, in essence, on seeing and being seen. For that reason, I position Twitch at the intersection of what David Lyon (2018) calls surveillance culture, the sense that watching and being watched has become fundamental to our customs, habits, and ways of interpreting the world, as well as surveillance capitalism, Soshana Zuboff's (2015) term for an emergent logic of accumulation in digital spaces built on widespread data collection. In both cases, Twitch offers insight into how, and in what ways, surveillance increasingly mediates contemporary cultural economies.

\section{Twitch, Plafforms, and Surveillance}

Twitch was founded in 2008 as Justin.tv. Unlike YouTube, which was then coming to prominence, Justin.tv afforded synchronous, asymmetric audio-visual communication between a broadcaster and their audience. ${ }^{1}$ Though Justin.tv was not the first livestreaming site, it succeeded in part because it reduced the cost of delivering one hour of live video to less than a penny, making ad-supported livestreaming a viable business model. Like many other sites built on user-generated content, Justin.tv grew rapidly throughout the late 2000s. In 2011, in part due to concerns over the volume of "pirated" streams hosted on the site (Bruns 2009), and in part due to the popularity of video game content on the site, Justin.tv rebranded as Twitch. To orient itself around gaming, the site adjusted its terms of service to ban any content that did not include live gameplay, going so far as to dictate what percentage of the screen could be occupied by a video feed of the streamer's face. In 2014, amid an exponentially increasing number of viewers and streamers, Amazon announced that it had purchased Twitch in an all-cash deal for $\$ 980$ million dollars.

In describing its product, Twitch adopts many of the performative and egalitarian connotations of "platform" that made the term appealing to tech companies in late 2000s (Gillespie, 2010). Scholarship on platforms frequently echoes this definitional flexibility. Whereas software studies tends to ontologize platforms in terms of programmability, scholars of political economy (Srnicek 2016) focus on how platforms facilitate vast multi-sided markets (Rieder and Sire 2014). Researchers interested in labor, by contrast, theorize platforms as "intermediaries" (van Doorn 2017). Twitch, which provides opportunities for self-expression, has an application programming interface (API), enables exchanges between unlike parties, and organizes labor at scale, is a platform according to each of these definitions. As a result, I adopt a knowingly open sense of platform that acknowledges each of these valences without suggesting that any one is the "true" definition. Platforms, like all things, are what they are only in context.

In response to this conceptual slippage, I also adopt John Gilliom and Torin Monahan's (2013: 3) permissive definition of surveillance as "monitoring people in order to regulate or govern their behavior," while also affirming that surveillance acquires different forms, purposes, and meanings across social contexts. The need for radical contextuality takes on particular importance in social and participatory media, which challenge top-down frameworks for surveillance and demonstrate the need to theorize alternate modes of post-panoptic and social surveillance (Marwick 2012). As Monahan and Murakami Wood (2018: 307) ask,

\footnotetext{
${ }^{1}$ In some ways, Mark Andrejevic (2008: 39) predicted the development and success of a service like Twitch in his early work on interactive television. As he writes, "in the digital future, watching will really be a form of participation precisely because we will be able to 'talk back' to the tube. The savvy subject will be realized in the form of the active viewer." As I will show, this description could have easily functioned as a pitch to Justin.tv's early investors.
} 
"how should we modify our explanatory frameworks to include the nuanced complexity of micro-level influence or the subtle production of social norms through social media interactions?" Twitch is a fruitful site for wrestling with this question. Given the complex interplay of sociotechnical and political economic relations on Twitch, and the variety of cultural production taking place, there is no one form of "surveillance" on Twitch, but, rather, an irreducible array of surveillant relations. Untangling them - if only to study their engagement - requires attending to the forms of seeing and being seen afforded to different actors in the platform ecosystem. I now turn to them.

\section{Streamers}

In her monograph on Twitch, Watch Me Play, T.L. Taylor (2018) argues that Twitch broadcasters engage in a kind of "transformative play," a form of labor that turns private gameplay into public entertainment through social practices and technical skills. While the ability to stream is not itself hardware intensive, professional streaming demands a complex assemblage of microphones, video cameras, green screens, second or even third monitors, fast, stable internet, and high-end computer hardware. A typical broadcast includes a live feed of the streamer's screen, as well as a webcam feed that displays streamers' reactions to in-game events and actions by the audience (see Figure 1). Twitch enthusiasts - viewers and streamersemphasize that "Twitch chat," a box that allows viewers to send pseudonymous text-based messages, as well as a growing number of extensions, is crucial to facilitating the interactive video experience that defines the platform for many. Thus, both viewers and streamers are invested in the degree to which they can react to and influence each other's actions.

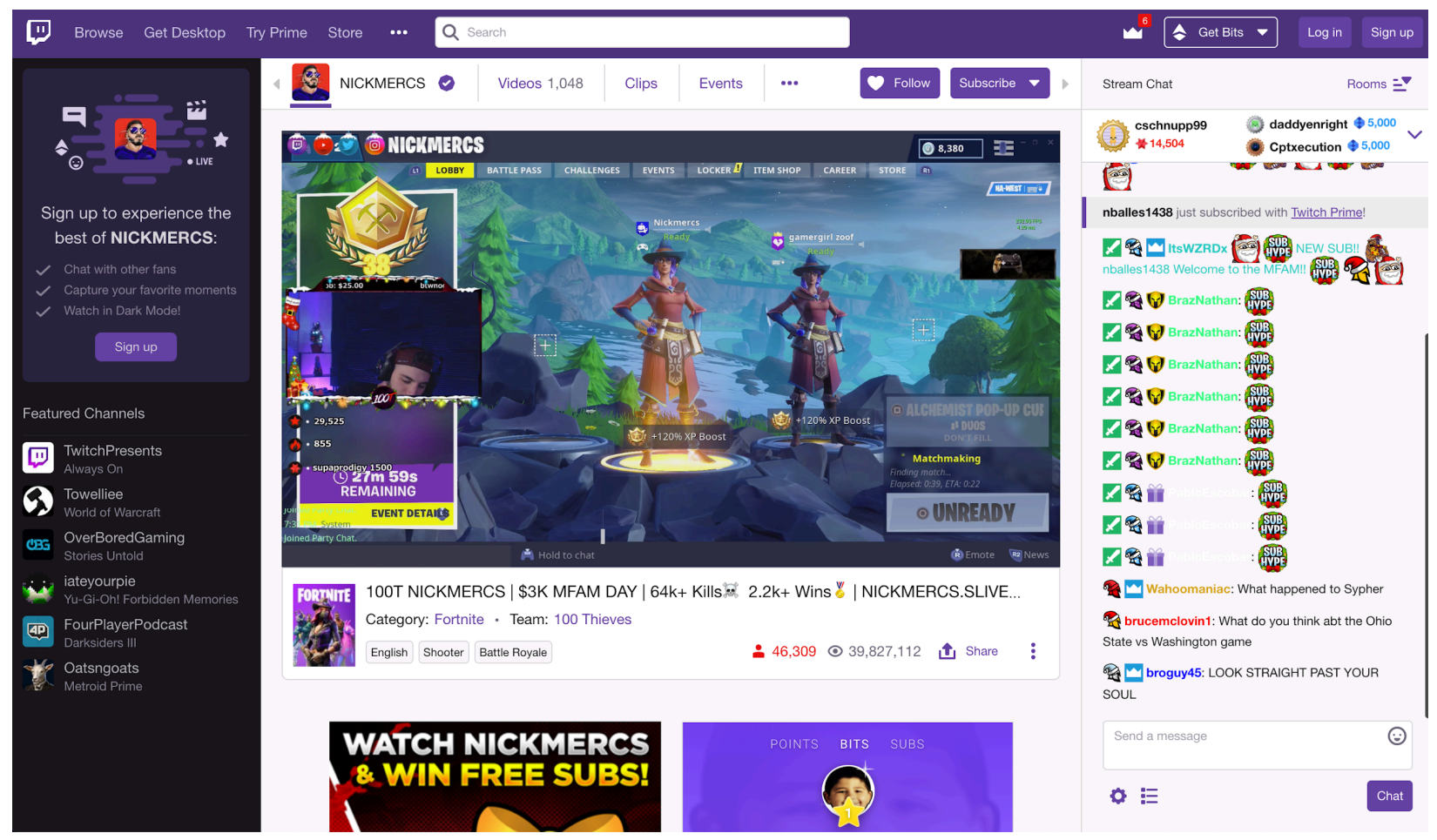

Figure 1: A screenshot of a typical livestream, displaying the live broadcast, chat box, and the rest of the user interface.

Echoing Daniel Trottier's (2012) work on how social media surveillance is simultaneous and multidirectional, Austin Walker (2014) argues in an early article on livestreaming published by this journal that streamers benefit from the new modes of "creative and collaborative" play Twitch affords. This is true: most streamers, amateur or professional, view Twitch an empowering tool for self-expression. Yet, as Walker notes, it is also true that streamers are subject to various "techniques and technologies of control 
and surveillance." Taylor (2018) has elaborated on this point, describing how streamers are embedded in the "regulatory assemblage" of networked broadcasting, the complex systems of governance and regulation that shape streamers' labor. As with other social media platforms, streamers must adhere to Twitch-imposed content guidelines that govern everything from hate speech to copyrighted content, the latter of which is monitored by algorithmic detection systems. At the same time, streamers are subjected to ongoing scrutiny by each other and their viewers. The policing of women's bodies by viewers, streamers, and Twitch itself (in debates over what constitutes "appropriate" attire for streaming shows) that visibility and surveillance on the platform is simultaneously bottom-up, lateral, and top-down (Alexandra 2018).

These relations are closely tied to the political economy of Twitch, which, as Hector Postigo (2016) notes of YouTube, is inextricable from its sociotechnical architecture. Mark Johnson and Jamie Woodcock (forthcoming) identify seven ways (as of 2018) in which streamers monetize their broadcasts: subscriptions, donations, advertising, sponsorships, on-air competitions, unpredictable rewards for viewers, and channel games. Though surveillance may be articulated to each of these, the role it plays is particularly apparent for donations. As Taylor (2018) notes, drawing on recent work by Nancy Baym (2018: 21), streamers perform constant relational labor, defined as "the ongoing, interactive, affective, material, and cognitive work of communicating with people over time in order to create structures that can support continued work," in order to present themselves as "worthy" of donations from viewers. Likewise, upon receiving donations, streamers are expected to perform gratitude appropriate to a given donation's amount: while a five-dollar donation may elicit a polite "thank you" from a streamer, $\$ 5,000$ demands a spectacular celebration (compilations of streamers receiving large donations has become its own subgenre on YouTube). Should streamers fail to present themselves as deserving or celebrate a large donation adequately, they risk being seen as ungrateful, imperiling their financial relationship with their audience. Thus, the sociotechnical underpinnings of the political economy of Twitch interpellate streamers such that they must endlessly monitor and modulate their behavior to appease a (potentially) paying audience.

\section{Viewers}

The productivity of audiences has long been a theme in the political economy of communication, going back to Dallas Smythe's (1973) formulation of the audience commodity, which described how audiences are produced and sold to advertisers - the "work," in a sense, of being watched. Smythe's arguments have received renewed interest in the age of social media, and scholars such as Christian Fuchs (2012) have demonstrated how Marx's concept of abstract labor is fully compatible with the various modalities of labor that social media relies upon. While watching streams, Twitch viewers, like other social media platforms, produce data that can be monetized via the development of data personas that can be sold to advertisers, predict market trends, or influence user behavior.

Even so, viewers are not passive and enact their own forms of agency within Twitch, which speak to their own self-presentation strategies and personal desires. As with any medium, viewer motivations for tuning into Twitch vary significantly among individuals. Uses and gratifications research (Hilvert-Bruce et al. 2018) has shown that while many viewers are eager to evaluate new games for purchase or improve their gaming skill by watching elite players, a plurality of viewers seeks sociality on Twitch. And because the social necessarily relies on the presence of others - not just the streamer who "creates" the broadcast space, but also those who answer the summons to tune in and interact - it is in part the audience that produces Twitch's appeal.

Viewers' approaches to becoming social are often tied to strategies of becoming visible, both to each other and to the streamers they follow. On this point, I have found Crystal Abidin's (2016: 90) notion of visibility labor, defined as "the work individuals do when they self-posture and curate their self-presentations so as to be noticeable," to be generative concept. Just as Abidin's informants-followers of Singaporean Instagram influencers - strategize about how and when to engage with certain posts, Twitch viewers carefully negotiate the technical affordances and social norms of Twitch. Importantly, however, visibility labor on Twitch is mediated by its political economy. While Twitch chat allows viewers to pseudonymously ask questions of streamers and other viewers, individual messages are often drowned out in broadcasts with 
thousands of viewers. In such cases, becoming visible requires making a donation, which will cause a viewer's name to appear on the stream and (in theory) be recognized by the streamer. Such messages may be supportive, taunting, or nakedly self-promotional. But regardless of intent, the work of "being seen" performed by viewers is an integral part of how streamers monetize the labor of livestreaming.

Likewise, Johnson and Woodcock (forthcoming) describe "channel games" as one strategy streamers use to monetize their audiences, affording such audiences an opportunity to become persistently visible. The most famous among these is the "Bit Boss," a

downloadable extension for one's stream which establishes a certain donor as being the "Boss" (Bits are Twitch's internal currency) other viewers can "attack" by donating further Bits. The individual who deals the final blow then becomes the Boss, and as a reward, their username and donation remain on-screen until they are defeated by a later donor.

Beyond the hypervisibility it affords to a single "winner," the Bit Boss channel game highlights the agency of the audience and casts attention on it as a collective, one capable of working together to achieve a specific goal. Importantly, however, this self-conscious call to action is circumscribed by Twitch's political economic terrain, benefiting both streamers and the platform owner.

\section{Twitch as Platform Owner}

Finally, Twitch - itself a part of Amazon's empire - echoes the broader logics of surveillance capitalism, defined by Zuboff (2015) as a model of institutionalized value accumulation in online spaces based on data collection. Surveillance capitalism monetizes data it extracts from users by developing consumer profileswhich, in this case, are linked to viewers' Amazon accounts - in order to map and predict trends, manipulate individual and group behavior, and sell collected data in markets that individual users are barred from participating in.

As I argue elsewhere (Partin forthcoming), Twitch has consistently moved to "capture" third-party services by creating first-party tools that replicate their functionality, which encloses the data these services produce about streamers and viewers alike. Streamers, for example, have long relied on third-party donation management services to process donations. In 2016, however, Twitch announced a similar service of its own, Twitch Bits, that would compete with these third-party services. Because of Twitch's ability design its own interface, Twitch automatically enrolls every streamer in the Bits program and gives Bits prime placement in its interface. These practices of "digital enclosure" (Andrejevic 2009) echo the broader logics of platform capitalism, wherein data is imagined as a "raw" resource to be expropriated and capitalized upon.

Twitch, like all platforms, also engages in various forms of algorithmic and manual content moderation and behavioral monitoring that recall earlier panoptic theories of surveillance. As Tarleton Gillespie (2018: 5) argues, "platforms must moderate: both to protect one user from another, or one group from its antagonists, and to remove the offensive, vile, or illegal." It is right, I believe, to expect Twitch to intervene when streamers broadcast obviously hateful or illegal content, or when streamers engage in abusive behaviors onair. $^{2}$

\footnotetext{
${ }^{2}$ That said, streamers, who are incentivized to pursue novelty in a cutthroat attentional economy often engage in practices designed to avoid scrutiny while broadcasting content that may violate Twitch's terms of service. In one well-known and humorous incident, streamer Lester_Gaming broadcast a copyrighted, pay-per-view Ultimate Fighting Championship match, while pretending he was "playing" the licensed UFC video game (Good 2017). Lester's novel deception was discovered when it went viral and led to a 24-hour ban from Twitch, but it nevertheless serves as a reminder that streamers actively attempt to circumvent or negotiate the regulatory assemblage into which they are interpellated.
} 
What gets moderated is necessarily political, however, and Twitch has often found itself in the uncomfortable position of adjudicating on content seen, fairly or not, as controversial. Disappointingly (if unsurprisingly) the effects of these rulings have been disproportionately borne by marginalized populations. Queer game designer Robert Yang, for example, has (in)famously had a number of his games about gay male sexuality banned from Twitch. "What's too gay for them? What's too sexual for them?,"Yang (2016) asked in a scathing op-ed for Polygon, noting too that Twitch has no provision against broadcasting a scene in the popular game The Witcher 3: Wild Hunt in which the protagonist tours a house filled with mutilated female corpses. Yang (2017) later responded to Twitch's censorship by releasing The Tearoom (see Figure 2), "a historical public bathroom simulator about anxiety, police surveillance, and sucking off other dudes' guns." In a wry move to avoid Twitch's ire (or, better yet, to highlight its incoherence), Yang replaced onscreen penises with a variety of firearms. "If they still ban my game," he wrote, "then it will be the first time in history that the game industry regulates and bans a game about guns."

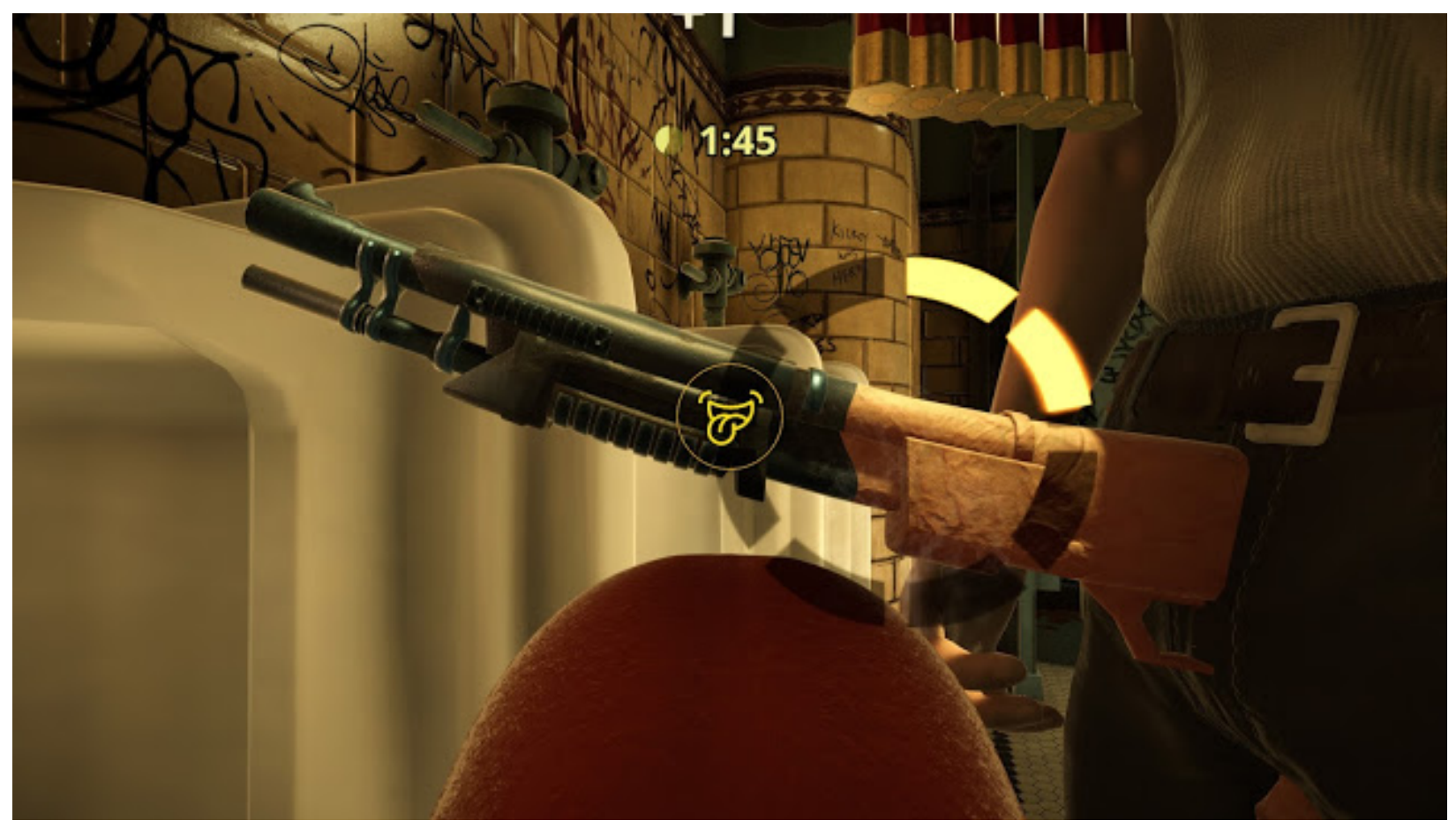

Figure 2: Screenshot from The Tearoom. Image courtesy of Robert Yang.

\section{Twitch as Boundary Object}

The case of Robert Yang and The Tearoom demonstrates that "streamers" and "viewers" are never abstractions but classed, raced, and gendered bodies embedded in online and offline communities. Scholars must attend to many contexts in which livestreaming occurs in order to disrupt technologically determinist narratives about platforms and their effects. I follow Taylor (2018) in suggesting that Twitch should be understood as what Geoffrey Bowker and Susan Leigh Star (1999: 297) call a boundary object, one that "[inhabits] several communities of practice and [satisfies] the informational requirements of each of them ... plastic enough to adapt to local needs and constraints of these several parties employing them, yet robust enough to maintain a common identity across sites." It is necessary for scholars to reconstruct the contexts in which livestreaming is taken up in order to understand where, how, and why it has been accepted. Put differently, platforms do not just mediate but are themselves mediated. Just as surveillance practices, 
infrastructures, and imaginaries co-produce their own situation, platforms' effects are context-dependent. Further research is necessary to fill out the empirical record and identify intervening variables.

As ever, the question that animates this research is "what differences make a difference?" I offer social identity as one difference among many. As surveillance studies has developed over the last twenty years, it has begun to account for how surveillance is experienced differently across populations and social identities, and it is principally through these differential effects that surveillance reproduces and naturalizes social, political, and economic inequalities. Not unlike how Simone Browne (2015) demonstrates how technologies of racialized surveillance have targeted black Americans, Kishonna Gray (2016) has documented the challenges black streamers face in a (white, cis-heteronormative, and patriarchal) hegemony that naturalizes white streamers as "normal." Black streamers, she argues, are often singled out as delegitimatized users"they're just too urban," as one commenter wrote-and are subject to increased scrutiny. Likewise, I have elsewhere (Partin 2018) explored how masculinized discourses of entrepreneurship construct male streamers as more "authentic" recipients of corporate sponsorships, whereas many women who pursue such deals are beleaguered by accusations of selling out or being "fake." In such cases, social surveillance plays an important role in dictating who can stream on Twitch, in what ways, and for what reasons. Explaining these phenomena requires engaging broader social ills that a technocentric approach may miss.

\section{Conclusion: Towards a Cultural Economy of Surveillance}

I end with the vignette with which I began. The case of Jason Gargac, the Uber driver-cum-Twitch streamer, is another reminder that Twitch is a flexible set of technologies that will be employed in ways beyond what its owners intended. So too will the contexts in which platform surveillance occurs shift. For this reason, we do well not to speak of platform surveillance, but of multiple and intersecting platform surveillances, the various and multiform practices of platform-based surveillance that rely on technical systems but are enacted by users afforded distinctive ways of performing. There is no platform surveillance, only platform surveillances.

In this note, I have attempted to speak about the heterogeneous forms of surveillance- some lateral, some panoptic; some (arguably) justifiable, and others troubling - that Twitch affords and how these forms of surveillance are often inextricable from the political economy of Twitch. Indeed, in many ways, they are the political economy of Twitch. In an age of mutually reinforcing surveillance culture and surveillance capitalism - of which Twitch is a prime example - it is no longer enough to speak of surveillance and political economy. Surveillance is a cultural economy all its own.

\section{Acknowledgments}

This paper emerged out of conversations in an independent study with Dr. Torin Monahan and Amrut Mishra. I am grateful to them, as well as my anonymous reviewer and Dr. Melissa Gregg, for their comments.

\section{References}

Abidin, Crystal. 2016. Visibility Labour: Engaging with Influencers' Fashion Brands and \#OOTD Advertorial Campaigns on Instagram. Media International Australia 161 (1): 86-100. https://doi.org/10.1177/1329878X16665177.

Alexandra, Heather. 2018. Twitch Gets New Policies For Sexual Content and Harassment. Kotaku (blog). February 8, 2018. https://kotaku.com/twitch-gets-new-policies-for-sexual-content-and-harassm-1822847804.

Andrejevic, Mark. 2008. Watching Television Without Pity: The Productivity of Online Fans. Television \& New Media 9 (1): 24-46. https://doi.org/10.1177/1527476407307241.

. 2009. Privacy, Exploitation, and The Digital Enclosure. Amsterdam Law Forum 1 (4). http://amsterdamlawforum.org/article/view/94/168.

Baym, Nancy. 2018. Playing to the Crowd: Musicians, Audiences, and the Intimate Work of Connection. New York: NYU Press.

Bowker, Geoffrey, and Susan Leigh Star. 1999. Sorting Things Out: Classification and Its Consequences. Cambridge: The MIT Press.

Browne, Simone. 2015. Dark Matters: On the Surveillance of Blackness. Durham: Duke University Press.

Bruns, Axel. 2009. The User-Led Disrutpion: Self-(Re)Broadcasting at Justin.TV and Elsewhere. Paper presented at EuroITV'09, Leuven, Belgium, June 3-5.

https://doi.org/10.1080/1369118X.2017.1294194. 
Fuchs, Christian. 2012. Dallas Smythe Today- The Audience Commodity, the Digital Labour Debate, Marxist Political Economy and Critical Theory. Prolegomena to a Digital Labour Theory of Value. TripleC: Communication, Capitalism \& Critique. Open Access Journal for a Global Sustainable Information Society 10 (2): 692-740.

Gillespie, Tarleton. 2010. The Politics of "Platforms." New Media \& Society 12 (3): 347-64. https://doi.org/10.1177/1461444809342738.

. 2018. Custodians of the Internet: Platforms, Content Moderation, and the Hidden Decisions That Shape Social Media. New Haven: Yale University Press.

Gilliom, John, and Torin Monahan. 2013. Supervision: An Introduction to the Surveillance Society. Chicago: University of Chicago Press.

Gray, Kishonna. 2016. “They’re Just Too Urban”: Black Gamers Streaming on Twitch. In Digital Sociologies, edited by Jesse Daniels, Karen Gregory, and Tressie Cottom. Bristol: Policy Press.

Heffernan, Erin. 2018a. St. Louis Uber Driver Put Video of Hundreds of Passengers Online. Most Have No Idea. St. Louis Dispatch, July 24, 2018. https:/www.stltoday.com/news/local/metro/st-louis-uber-driver-put-video-of-hundreds-ofpassengers/article 9060fd2f-f683-5321-8c67-ebba5559c753.html.

-2018b. Uber Evaluating Policies in Response to Story on St. Louis Driver's Secret. St. Louis Dispatch, July $24,2018$. https://www.stltoday.com/news/local/metro/uber-evaluating-policies-in-response-to-story-on-st-louis/article 7c8e4558ff49-54c0-8e8c-a6e79b954325.html.

Hilvert-Bruce, Zorah, James T. Neill, Max Sjöblom, and Juho Hamari. 2018. Social Motivations of Live-Streaming Viewer Engagement on Twitch. Computers in Human Behavior 84 (July): 58-67. https://doi.org/10.1016/j.chb.2018.02.013.

Johnson, Mark R., and Jamie Woodcock. forthcoming. “And Today's Top Donator Is": How Live Streamers on Twitch.t Monetize and Gamify Their Broadcasts. Social Media + Society.

Lyon, David. 2018. The Culture of Surveillance. London: Polity.

Marwick, Alice. 2012. The Public Domain: Social Surveillance in Everyday Life. Surveillance \& Society 9 (4): $378-93$.

Monahan, Torin, and David Murakami Wood, eds. 2018. Surveillance Studies: A Reader. Oxford: Oxford University Press.

Nieborg, David B, and Thomas Poell. 2018. The Platformization of Cultural Production: Theorizing the Contingent Cultural Commodity. Social Media + Society, 18.

Partin, Will. 2018. "Get Paid Homie!” Aspiration, Masculinity, and the Labor of Livestreaming. Paper Presented at Association of Internet Researchers, Montréal, Canada, October 10-13.

- forthcoming. Bit by (Twitch) Bit: From Platform Envelopment to Platform Capture. Social Media + Society, NP.

Postigo, Hector. 2016. The Socio-Technical Architecture of Digital Labor: Converting Play into YouTube Money. New Media \& Society 18 (2): 332-49. https://doi.org/10.1177/1461444814541527.

Rieder, Bernhard, and Guillaume Sire. 2014. Conflicts of Interest and Incentives to Bias: A Microeconomic Critique of Google's Tangled Position on the Web. New Media \& Society 16 (2): 195-211. https://doi.org/10.1177/1461444813481195.

Smythe, Dallas W. 1981. Dependency Road: Communications, Capitalism, Consciousness, and Canada. Norwood, NJ: Ablex. Srnicek, Nick. 2016. Platform Capitalism. Cambridge: Polity.

Taylor, T.L. 2018. Watch Me Play: Twitch and the Rise of Game Livestreaming. Princeton: Princeton University Press.

Trottier, Daniel. 2012. Social Media as Surveillance: Rethinking Visibility in a Converging World. Surrey: Ashgate Publishing.

van Doorn, Niels. 2017. Platform Labor: On the Gendered and Racialized Exploitation of Low-Income Service Work in the "onDemand" Economy. Information, Communication \& Society 20 (6): 898-914.

Walker, Austin. 2014. Watching Us Play: Postures and Platforms of Live Streaming. Surveillance \& Society 12 (2): $437-42$.

Yang, Robert. 2016. Why I Am One of the Most-Banned Developers on Twitch. Polygon. July 14, 2016. https://www.polygon.com/2016/7/14/12187898/banned-on-twitch. . 2017. The Tearoom as a Record of Risky Business. Radiator (blog). 2017. https://www.blog.radiator.debacle.us/2017/06/the-tearoom-as-record-of-risky-business.html.

Zuboff, Shoshana. 2015. Big Other: Surveillance Capitalism and the Prospects of an Information Civilization. Journal of Information Technology 30 (1): 75-89. https://doi.org/10.1057/jit.2015.5. 